\title{
Palabras e imágenes, objetos y acciones en la postvanguardia chilena*
}

\author{
Words and images, objects and actions in Chilean post-vanguard \\ Oscar Galindo V. \\ Universidad Austral de Chile, Instituto de Lingüística y Literatura, \\ Apartado Postal 567, Valdivia, Chile. \\ e-mailogalindo@uach.cl
}

Este artículo analiza una zona de la productividad poética postvanguardista chilena con el propósito de explorar en los entrecruzamientos entre palabras, imágenes, objetos y acciones en la obra de Enrique Lihn, Gonzalo Millán, Juan Luis Martínez y Raúl Zurita, entre otros. Se trata de una discursividad que ha otorgado un nuevo dinamismo a la poesía chilena, provocando una escritura heterogénea y mutable en la construcción de nuevos debates en la poesía chilena contemporánea.

Palabras clave: postvanguardia, poema cuadro, poema concreto, poema objetual, poema acción.

This paper analyses a section of the Chilean post-vanguard poetic productivity with the purpose of exploring intertwined words, images, objects and actions in Enrique Lihn, Gonzalo Millan, Juan Luis Martinez and Raul Zurita's poetry. The study centers on discourse poetry which has given some new dynamics to Chilean poetry causing a mutable and heterogeneous writing in the construction of new debates in contemporary Chilean poetry.

Key words: post-vanguard, image poetry, concrete poetry, object poetry, action poetry.

\section{INTRODUCCIÓN}

En su lúcido ensayo sobre Magritte Esto no es una pipa, variaciones a su vez de las distintas versiones en que Magritte combinaba palabras e imágenes para afirmar que lo que se pinta no es lo que se representa, Foucault escribió que "pintar no es afirmar" y que "El caligrama pretende borrar lúdicamente las más viejas oposiciones de nuestra civilización alfabética: mostrar y nombrar; figurar y decir; reproducir y articular; imitar y significar; mirar y leer" (1981:34). Este artículo explora en las nuevas retóricas que han emergido en la poesía chilena de tradición vanguardista, como resultado del reprocesamiento de prácticas poéticas precedentes que intentan superar la noción de palabra como eje constructor del poema: cuando para los poetas las palabras son cosas y las cosas pueden llegar a ser palabras. Se explora en los entrecruzamientos entre palabra e imagen, objeto y acción, a partir de la lectura de textos de Enrique Lihn, Gonzalo Millán, Juan Luis Martínez y Raúl Zurita, preferentemente. Se trata (es nuestra hipótesis) de una discursividad que ha otorgado un nuevo dinamismo a la poesía chilena provocando una escritura heterogénea y mutable, en la instalación de nuevos debates culturales. Experimentación textual que aspira a recuperar la tradición polémica de la vanguardia no sólo en el terreno de los procedimientos poéticos, sino también en su "intromisión" en el debate social, en un conflictivo cruce entre la opacidad comunicativa y el diálogo (Cánovas 1986; Triviños 1988; Carrasco 1989). Se trata de una operación semiótica de expansión de los códigos expresivos de la lírica cuyos antecedentes se encuentran en la primera vanguardia, en el pop art y en la poesía concreta; así como la transposición de elementos de un sistema de significación a otro (poesía y plástica como la más visible); pero al mismo tiempo supone una operación política en la medida en que se introducen nuevos parámetros dialógicos, al "injertarse" con otras disciplinas, desbordándolas. La postvanguardia es el resultado de la desconfianza en el lenguaje y sus trampas, en la retórica inflamada y mesiánica. Dedicada a desestabilizar otros sistemas discursivos por medio de la parodia, la ironía, el silencio y, sobre todo, de la crítica al propio discurso, la poesía se convierte en contralenguaje. La devaluación del lenguaje poético, y del lenguaje en sí mismo está vinculada también a una caída en "la trampa de la historia" al decir de Sucre (1985: 278-292), en la que al poeta le corresponde la tarea del transeúnte y en la que participa por exclusión.

La crítica tímidamente ha ido incorporando una serie de categorías que intentan explicar la relación entre poema y artes visuales: poema cuadro (ékfrasis), poema concreto, poema objetual, poema encontrado (ready made); podríamos hablar también de otras posibilidades: poema híbrido, poema 
acción, poema instalación, poema filme. No se ha hecho la historia de las relaciones entre poesía y plástica en la poesía chilena, pero podemos mencionar al menos tres antecedentes relevantes: los caligramas y poemas pintados de Vicente Huidobro en los años 20; los collages poéticos de Ludwig Zeller y "El quebrantahuesos" de Parra, Lihn y Jodorowsky. La eclosión se produce a fines de los años 70. Fundamentales en la reflexión sobre arte conceptual y poesía han sido Ronald Kay, junto a Eugenio Dittborn y Catalina Parra, con el grupo VISUAL (1977). A esas alturas ya teníamos los Artefactos (1972) de Nicanor Parra y de 1977 es también La nueva novela de Juan Luis Martínez. En 1979 se publica Anteparaíso de Raúl Zurita, aunque un par de años antes se habían publicado algunos avances en la mítica revista Manuscritos 1. A partir de los años 80 Enrique Lihn trabaja en la incorporación de fotografías, plástica y videos a sus creaciones artísticas. En la plástica, Lepe, Altamirano y Smythe utilizan fotografías, textos y objetos en la elaboración de sus cuadros conceptuales. A principios de los 80 Dittborn, Rosenfeld, Zurita, Eltit, entre otros, incorporan las acciones de arte a su imaginario poético, narrativo, plástico o videístico.

EL POEMA CUADRO: ENRIQUE LIHN Y GONZALO MILLÁN

En la retórica clásica se distinguía la ékfrasis para referirse a aquel tipo de texto que se fundaba en la imitación de un hecho plástico. Hoefler señala que el poema cuadro es un texto poético cuyo asunto "referencia anterior, inter o intratexto, modelo o contratexto es una obra plástica, ya sea una escultura, un cuadro, una obra gráfica, un camafeo o como se propone recientemente un filme o una fotografía" (1993: 553). En tanto textualidad fundada en un modelo, creo que el poema cuadro es una nueva versión de la actitud noemanierista que caracteriza buena parte de la poesía contemporánea ${ }^{1}$.

De la permanente preocupación de Enrique Lihn (1929-1988) por las relaciones entre poesía y artes visuales dan cuenta sus exploraciones en las artes escénicas, videísticas y fotográficas. El mismo Lihn fue ocasionalmente productor de obras plásticas, pero es en su poesía donde se advierte la utilización de la retórica ekfrástica. Este recurso es especialmente visible en A partir de Manhattan (1979). En su afán por construir un lenguaje como observación de espacios urbanos, las calles, el metro y los museos son espacios privilegiados. Especialmente el museo, en tanto lugar de almacenaje de productos artísticos y escenificación de la mirada. En el poemario se pueden encontrar textos referidos a las obra de Edward Hopper, Francis Bacon, Gerard David y, especialmente, de Claude Monet. Notable es el poema "Water Lilies, 1920" como expresión de un poema cuadro:

A su edad más avanzada cantó

el acrecido pájaro de la pintura

y el viejo Monet alcanzó su verdad escurridiza

como el aire que riza estas lagunas monumentales

telones que hacen innecesaria otra ópera

preciosos de légamos y herrumbres música que alimenta a los nenúfares

actores solitarios de la nada en que flotan.

Un cielo especular

es todo lo que se ve del agua

invisible que lo refleja.

Otro ejemplo notable en la utilización del poema cuadro es Gonzalo Millán (1947-2006). Al igual que Enrique Lihn, sus preocupaciones por la plástica alcanzan la docencia y la ocasional realización de collages paralelos a su poesía. Su producción puede, en un sentido amplio, ser leída como una poética de la mirada, pero es la publicación de Claroscuro (2002) la expresión más compleja y sistemática de esta retórica en la poesía chilena contemporánea. Claroscuro se estructura en tres secciones, todas ellas basadas en la descripción de obras de los artistas barrocos: Caravaggio y Zurbarán ${ }^{2}$. La propuesta de Millán surge no sólo de la admiración hacia ambos pintores barrocos naturalistas, sino principalmente del afán de explorar en los fundamentos de la escritura y en su propio proyecto poético, coincidente con ambos artistas barrocos en la preocupación intelectual por las relaciones entre arte y (re)presentación. Claroscuro puede ser leído como un texto metapoético y autorreflexivo, fruto extremo de las posibilidades de la intertextualidad neomanierista de la escritura.

\footnotetext{
${ }^{1}$ Gilbert Dubois logró establecer los elementos centrales de un modo de producción artística que denominó como manierista. Esto es "a la manera de". Si ese período entre Renacimiento y Barroco recibió el nombre de manierismo, en su complejo edípico de no poder liberarse del padre artístico (el Renacimiento), la metáfora biologicista utilizada por Dubois establece un principio fundamental: "los artistas se colocan bajo un modelo magistral y reivindican como un honor el derecho a reproducirlo" (1980: 11). Pero la imitación está muy cercana al remedo y el remedo se establece por medio de la exageración, de la hiperbolización, de las formas imitadas: "La obra manierista que se ajusta a la regla al punto de pervertirla por exceso de celo, supone paradójicamente una liberación de energía anarquizante y paranoica" (1980: 12).

${ }^{2}$ El trabajo más completo hasta la fecha sobre Claroscuro es la tesis de licenciatura de Carla Morales E. (2006) "Claroscuro de Gonzalo Millán: barroco y textualidad interartística".
} 
En las diapositivas de Santa Agueda, por ejemplo, observamos la descripción verbal de los elementos representados por Zurbarán. La descripción impersonal recuerda los afanes objetivistas de Millán ${ }^{3}$, quien pone especial atención en los objetos y en su materialidad pictórica:

La santa es una joven delicada

de mutilados pechos

vestida con boato, púrpura,

morado, negro y dorado.

\author{
La joven muestra el símbolo \\ de su martirio; los pechos \\ flotando sobre la sangre \\ que recoge una bandeja. (Primera Visión 1)
}

La utilización del recurso ekfrástico en la poesía chilena tiene mucho que ver con el cambio del modelo del sujeto que habla al sujeto que mira. De la voz a la mirada. De la subjetividad a la metatextualidad. Si bien prevalece el uso de la palabra para describir el objeto "presentado", no es posible leer sin la relación interartística necesaria para su comprensión.

\section{POEMAS CONCRETOS Y OBJETUALES: JUAN LUIS MARTÍNEZ}

La crisis de la representación bidimensional se hace presente en la plástica chilena a partir de la década del sesenta. Para Ivelic y Galaz la inestabilidad social conduce a los intelectuales de la época a "la reformulación de aquellos referentes (políticos, económicos, sociales, culturales), que pongan de manifiesto la situación problemática en la que se encuentra la comunidad nacional" (1988:152). Lo anterior supone que el espacio de dominio del arte se amplía hacia otros elementos externos al tradicional producto artístico (pintura, escultura o poema), incorporando "la realidad" al proceso de semiotización artística, por ejemplo, por medio de la incorporación de diarios, publicidad o fotografías. Lo propio ocurre en la escritura poética que incorpora frases hechas, publicitarias, chistes y, en fin, diversos "desechos" lingüísticos y culturales. Los principales elementos intervenidos tienen que ver con las cadenas de consumo y de comunicación, como ocurre con "El Quebrantahuesos" de Parra, Lihn y Jodorowsky. El ready made, el poema encontrado, son elementos sobre los cuales el poeta trabaja, apropiándose de la cultura de desecho y otorgando a la acción receptora un rol inusitado en las producciones precedentes. Un elemento relevante tiene que ver con los aportes de los poetas concretos, que trataban en lo medular, de subrayar el redescubrimiento del carácter material del lenguaje. La equiparación de lo "concreto" con lo "real", en la significación del término, ha sido utilizada por casi todos los poetas de esta tendencia (Onetto 2004: 191$202)^{4}$. Como es sabido los poetas concretos buscaban presentar el texto de forma libre sobre el espacio, lo que aporta la sensación de dimensión material de las palabras, desarticulando la sintaxis tradicional, por medio de la presentación en lugar de la representación.

Uno de los elementos más notables de La Nueva Novela (1977) de Juan Luis Martínez (1942-1993) es su capacidad para ampliar el soporte significante del texto ${ }^{5}$. Frente a la noción tradicional del poema como unidad de palabras, ofrece una pluralidad semiótica. La expansión de los soportes lingüísticos como base de la escritura poética constituye una de las claves de la poesía de la vanguardia y se proyecta al pop art y a la poesía concreta y es inseparable de la historia de la literatura desde Carroll y Mallarmé hasta

\footnotetext{
3 La noción de "poesía objetiva” que ha acuñado Millán para referirse a su propia práctica poética supone no la representación "objetiva" del extratexto, sino considerar que el lenguaje es la única realidad a la que puede apelar la escritura. Objetiva en la medida en que al prescindir de la intermediación del sujeto, aflora una mirada que surge de la relación entre los propios elementos del texto. Una buena explicación de lo que entiende por poesía objetiva es la siguiente: "Poesía objetiva por su preferencia por lo que está ante uno, lo concreto, y por su carácter impersonal, distante, neutro; por el empleo de ese hablante que no vierte directamente sus afectos y sentimientos ni tampoco enjuicia ni comenta" (Chihuailaf y Eytel 1985: 17).

4 "El impulso decisivo para el desarrollo del concepto de poesía concreta, empero, lo realizó Eugen Gomringer y el grupo brasileño Noigandres (el nombre lo tomaron del Canto XX, de Ezra Pound), quienes acordaron la denominación última de aquella poesía como "concreta", a mediados de los años cincuenta, hecho que fue ya la confirmación internacional de esta nueva tendencia en la literatura. El documento más importante del Grupo brasileño, fundado en 1952, por los poetas Augusto de Campos, Haroldo de Campos, y Dêcio Pignatari, fue el escrito firmado por los tres, y aparecido recién íntegramente en 1958, llamado Plano-Pilôto para Poesia Concreta. El principio estructural de sus textos lo denominaron: isomorfismo. Con ello aludían a la construcción del texto, que se iba armando por igual en distintos planos: a nivel sonoro, de imagen y de significación del material del lenguaje; en la práctica, el texto no busca representar decursos complejos de contenido, como en un discurso regulado sintácticamente, sino mostrar mediante la presentación de unidades lingüísticas repartidas sobre la superficie, un oscilar constante entre sus valores semánticos, acústicos y ópticos" (Onetto 2004: 193).

5 Juan Luis Martínez es autor además de una notable obra visual y objetual paralela e integrada a su producción escritural. Autor de collages, "cuadros" y objetos escultóricos, lamentablemente inaccesibles en colecciones públicas o exposiciones. Sobre este campo de trabajo de Martínez ha escrito José de Nordenflycht Concha (2001), quien además ofrece la mejor reproducción fotográfica del "Catálogo de la colección de Eliana Rodríguez de Martínez".
} 
nuestros días. Dicha expansión está ligada, en lo básico, a la ruptura de las convenciones románticas de la poesía como expresión personal, pero es, además, uno de los síntomas de la crisis de los discursos estables en el arte contemporáneo, de la crítica a la institucionalidad artística y de la apropiación del proyecto arte-vida como parte de una visión crítica de la modernidad.

La nueva Novela se construye como una propuesta artística plural en que se hibridan fundamentalmente tres soportes: el discursivo, el visual y el objetual. Cada página amplía el soporte lingüístico, ya sea por medio de la incorporación de dibujos, fotografías y objetos, como por la disposición gráfica intencional de las palabras en los espacios en blanco (Galindo 2000). El texto objeto subvierte la relación tradicional "representacionalista" entre el lenguaje y las cosas del mundo ${ }^{6}$, al ofrecer como signo al propio objeto que se alude en el lenguaje. La distancia entre el objeto designado y el lenguaje ofrece la paradoja de la imposibilidad de uno de ser representado por el otro, y de poseer simultáneamente conciencia de su propia materialidad. Desde otro punto de vista, la identidad entre referente y lenguaje es imposible, por tanto el lenguaje no podrá nunca observarse a sí mismo (Cf. "Un problema transparente").

Es en este espacio en que el signo (el arte) no puede convertirse en realidad y que la realidad no puede convertirse en lenguaje, en el que se sitúa la problematización. Como en otras ocasiones se trata de un problema que carece de solución como no sea en términos paradójicos. Se trataría de la irónica propuesta de un "lenguaje objetivo", pues se construye de los objetos sin más.

La construcción de La Nueva Novela como un complejo discursivo, visual y objetual supone el diálogo entre escritura, imágenes y objetos. Aparece en el texto "Icthys" (p. 71), de la sección "La zoología", en que encontramos adheridos dos anzuelos, uno en la parte superior y otro en la inferior: metáfora de Cristo como pescador y los hombres como peces. Reaparece en "La página en blanco" de la sección "La Literatura", en "La poesía china" (p. 97 de la misma sección), reproducción de una página impresa en chino sobre papel de arroz; en "Epígrafe para un libro condenado: la política" que se abre con una banderita chilena, convirtiendo a la patria en el lugar de la inmolación. En fin, nuevamente encontramos el mismo recurso en "Portrait of a lady" de la misma sección que incluye, frente a la fotografía de una mujer llorosa, una hoja de papel secante. Síntesis de la propuesta de Martínez: palabra, imagen y objeto.

\footnotetext{
${ }^{6}$ En su crítica al "representacionalismo", Francois Recanati señala que una de las bases de la concepción clásica del signo y de muchas escuelas modernas está dada por la noción de que el signo es algo que representa siempre algo distinto. Esta idea habitual del lenguaje, como transparente en su relación con las cosas y de su opacidad en la medida en que se torna autorreflexivo, le lleva a destacar la necesaria alternatividad que debe existir al considerar el signo y su significado: "Para explicar que las cosas (los signos) pueden de este modo representar otras cosas, el representacionalismo les atribuye la propiedad de desaparecer de alguna manera delante de ellas, y esta propiedad se concibe en analogía con la transparencia de ciertos objetos físicos. Un enunciado declarativo, que representa un estado de cosas o un hecho, es en sí mismo, por su enunciación un hecho; pero este hecho está puesto entre paréntesis y gracias a esta puesta entre paréntesis del hecho de su enunciación, el enunciado puede representar lo que representa. Si los signos fueran considerados cosas y los enunciados, hechos, perderían esta transparencia sin la cual sería incomprensible la propiedad que tienen de "significar" algo distinto de ellos mismos. Por este motivo, el signo y lo que él significa y representa, no pueden ser tomados en consideración simultáneamente, sino alternativamente, pues si se toma en cuenta lo que el signo es en tanto cosa, se opaca y pierde su virtud representativa; de esto se sigue que un signo no puede autorrepresentarse reflexivamente". (1981: 9).
} 


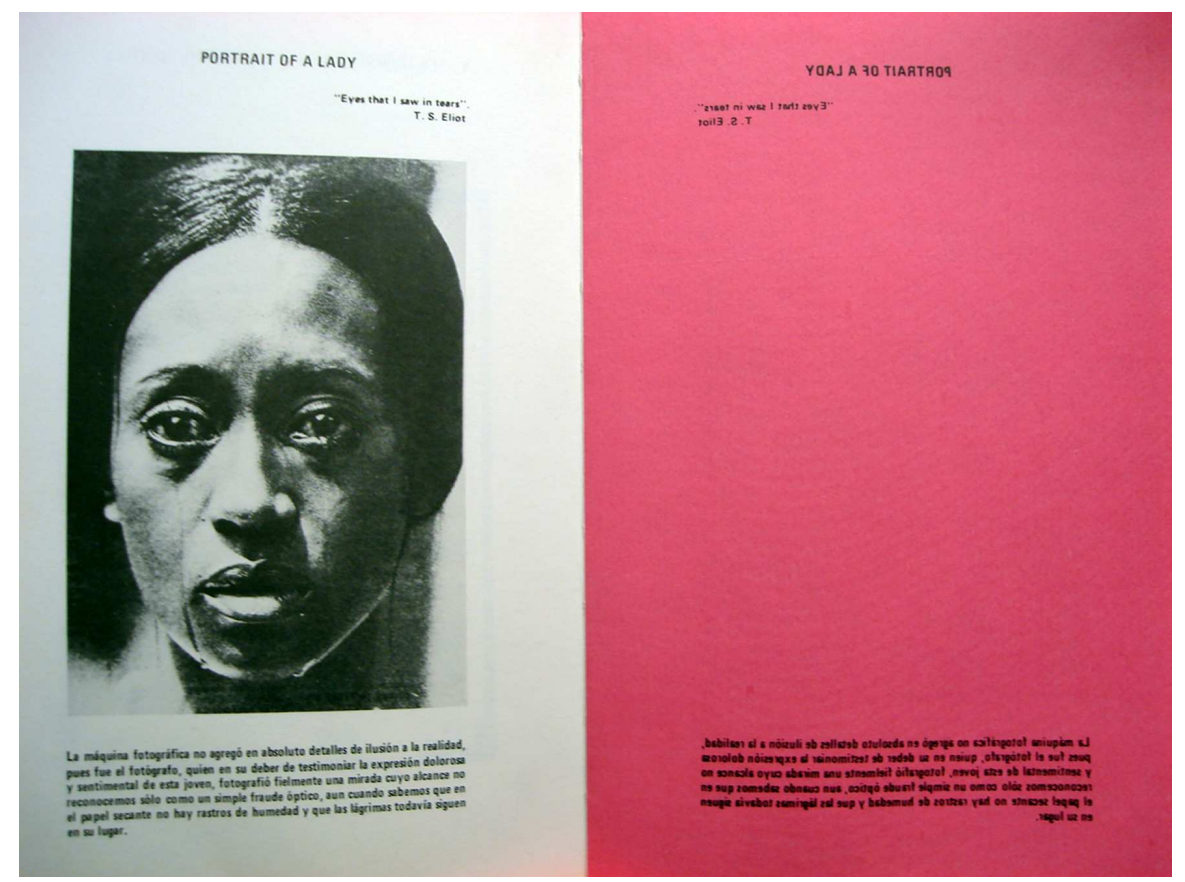

El proyecto de superación de la institución poética provoca un proceso de desarticulación de un proyecto local (la poesía chilena) y de un proyecto cultural global (la poesía moderna). La posibilidad de transformación de este lenguaje gastado en un nuevo lenguaje se resume en la parodia. La deconstrucción de un lenguaje opaco y su reemplazo por otro transparente culmina en un círculo del que no es posible escapar. La deconstrucción del programa de la poesía moderna no impide, sin embargo, que tras esta escritura continúen leyéndose las huellas del lenguaje que lo provoca. Poesía e historia se encuentran en el fracaso de sus tentativas y en sus tentativas se vuelcan permanentemente sobre la realidad. El lenguaje encuentra en la reconstrucción su principio de organización. La nueva novela des-en-can-ta el canto de la poesía moderna, parodia y refunda (Cf. "Observaciones relacionadas con la exuberante actividad de la confabulación fonética o lenguaje de los pájaros en las obras de J. P. Brisset, R. Roussel, M. Duchamp y otros").

El segundo libro de Martínez, La poesía chilena (1978) puede ser leído en este sentido. La interesante factura de este nuevo libro objeto convierte a su soporte en significante material de la escritura y resume en sus breves textos y en sus vacíos (en sus silencios) el flujo y una cierta continuidad de la poesía chilena. El libro se articula en diversos niveles de significación: primero, una caja negra que cubre el libro propiamente tal; segundo, el libro que desarrolla la unidad central; tercero, una bolsa de polietileno que guarda en su interior una pequeña cantidad de tierra, acompañado de la lectura "Tierra del valle central de Chile". El primer nivel se puede leer en el sentido de negación de libertad, clausura o encierro, y, por oposición, como necesidad de ruptura, de franqueamiento de una prohibición, de transgresión que debe ser ejercida desde su mismo interior. El segundo nivel se inicia en la portada del libro con un llamado apenas legible a la ruptura, a destruir los límites de una prohibición, a través de la violencia, desde un margen en que un sujeto periférico en la escena internacional del arte se alza como posibilidad de cambio ${ }^{7}$.

\footnotetext{
${ }^{7}$ El texto completo en la primera página del volumen, sobre franjas negras permite leer: AB IMO PECTORE*

Existe la prohibición de cruzar una línea que sólo Es imaginaria

(La última posibilidad de franquear ese límite se concretaría mediante la violencia):

Ya en ese límite, mi padre muerto me entrega estos

Papeles:

Loc. Lat.: (Desde el fondo del pecho)
} 
La proyección de este híbrido textual la encontramos en las curiosas páginas del libro que leen la continuidad de la poesía chilena por medio de dos soportes. En primer lugar, la presencia de la muerte en cuatro certificados de defunción superpuestos sobre una ficha bibliográfica. Los nombres de Lucila Godoy A., Pablo Neruda, Carlos Díaz Loyola y Vicente García Huidobro y F. se superponen a una ficha en la que se indica el nombre del libro, lugar, año de edición y título del poema, en cada caso alusivo a la muerte: "Sonetos de la muerte", "Sólo la muerte", "Poesía funeraria" y "Coronación de la muerte", respectivamente. En segundo lugar, una serie de banderitas chilenas superpuestas de igual modo sobre fichas bibliográficas que aparecen ahora vacías. Este procedimiento se mantiene hasta el final del volumen en que nos encontramos con un nuevo certificado de defunción, ahora de Luis Guillermo Martínez Villablanca, en cuya ficha se incluye el título de un supuesto poema "Tierra del valle central de Chile". Ya sabemos, de esta manera, que el texto no se orienta hacia el final, sino hacia el principio. El cuerpo de la muerte cuya presencia se vuelve un poema material, en su expresión material: tierra del valle central de Chile. La transgresión, el cruce de la prohibición nos ubica en las posibilidades de una poesía objetual. El mejor poema concreto es el objeto mismo una vez más. Este cruce provoca un cambio de lectura al introducir una posibilidad disímil, puramente personal e individual, en la continuidad descrita como "la poesía chilena". La relación del texto con el extratexto ejerce el sentido de violencia sobre una institucionalidad cultural convencionalizada y fosilizada y, en este sentido, desvitalizada y difunta. La poesía chilena así es reducida a estereotipos que operan en la conciencia colectiva como la manifestación de una manipulación sobre sus usuarios (los poetas, los lectores). Este sentido encuentra, además, su justificación en dos fotografías que se incluyen tanto en la portada como en la contraportada de dicho texto. Primero, una fotografía de James King (del Instituto de Arte Experimental, Texas) que reproduce el cráneo rapado de un sujeto con una estrella en el centro. Segundo, una fragmentación fotográfica del autor, titulado "Lavamanos" que recuerda a uno de los íconos textuales de Martínez (M. Duchamp). Ambas imágenes recuerdan la idea de la poesía del cuerpo y del ready made; es decir, de la cultura vital y de los objetos de la realidad por sobre la institución del arte ${ }^{8}$.

\section{POEMA ACCIÓN: RAÚL ZURITA}

La interrelación entre escritura y performance o acción artística es otro de los elementos relevantes del problema. Intentaremos explicar esta relación a partir de una experiencia concreta: el Colectivo de Acciones de Arte (CADA). Las iniciativas de este colectivo forman parte de este proyecto y justifican esta visión del arte como un medio de intervención y de modificación del curso histórico (1982:3). La relevancia de las acciones de arte del grupo CADA ha sido puesto de manifiesto por Nelly Richard $(1994)^{9}$. En este caso nos interesan las interacciones que esta productividad tuvo con un proyecto poético específico, el de Raúl Zurita. Es necesario distinguir entre las "acciones de arte" propiamente tal, como las realizadas por CADA de las acciones de Zurita que posteriormente se incorporan a su poesía. Las primeras suponen una acción de agitación, generalmente fugaz y colectiva (por ejemplo, "Para no morir de hambre en el arte” (1979) y “¡Ay Sudamérica!” (1981) ${ }^{10}$. Las segundas se escapan a la acción de

\footnotetext{
${ }^{8}$ Otros ejemplos de la utilización poemas concretos e híbridos textuales se encuentran en Raúl Zurita (Purgatorio, 1979), Mauricio Rosenman Taub (Alteration, 1997) y Andrés Anwandter (Square Poems, 2002).

9 "Una mirada sobre el desarrollo artístico nacional señala como "la evolución del arte en Chile, desde fines de los 50, puede ser descrita como una serie de modernizaciones" tendiente a constituir una modernidad del arte, consciente de sí misma y organizada (...) como campo de indagaciones y ejecuciones que busca incidir "en todos los nudos del circuito de producción artística; en la obra, en el productor, en el público, en las relaciones múltiples entre ellos, en la fijación institucional de esas relaciones, en las determinaciones del arte mismo y de su nexo con lo real" (Richard 1994: 37).

10 La primera consistió, entre otras acciones, en el reparto de 100 litros de leche en un sector popular de Santiago. La segunda, en el lanzamiento de cuatrocientos mil volantes desde aviones sobre Santiago, con un panfleto titulado Ay, Sudamérica que
} 
agitación para constituir correlatos de su escritura, por ejemplo, la quemadura de su rostro, cuya fotografía se incorpora a la primera edición de Purgatorio o el intento de cegarse con ácido, cuyo relato (a cargo de Diamela Eltit) cierra la primera edición de Anteparaíso (1982). La utilización del propio cuerpo como espacio de arte y de intervención, supone que la experiencia personal, la historia de vida, es la única historia que merece ser contada. Una tercera dimensión es la ejecución de acciones de arte en escenarios públicos que posteriormente pasan a formar parte de sus libros, o en palabras más precisas, son parte de dichos libros. Es lo que ocurre, por ejemplo, con las intervenciones en el paisaje: la escritura con humo de aviones sobre el firmamento de Nueva York ${ }^{11}$ (1982) de un texto en español que se incorpora a Anteparaíso ${ }^{12}$ y, más recientemente (1993), la escritura en el desierto de Atacama de la frase de más de 3 kilómetros "Ni pena, ni miedo" (1993) que se incorpora a La vida nueva (1994) $)^{13}$.

http://www.geo-trotter.com

La poesía y el arte no se entienden como productos autónomos, sino como parte de un proyecto en que arte y vida se interrelacionan y se modifican. De esta manera, el proyecto poético personal dejará su fetichismo para integrarse, como señala Zurita, en uno de sus primeros manifiestos, como otro lugar más, "al desarrollo colectivo del que dependerá su propia consumación. Esto significa asumir la construcción de un nuevo modelo social como lugar físico de cumplimiento de la obra, incorporada a la producción del Área Mundial en que cada UNO ERIGIRÁ SU PROPIA EXPERIENCIA Y LA DE LOS OTROS COMO EL ÚNICO PRODUCTO DE ARTE QUE MERECE SER COLECTIVIZADO”. (1979: 11). La articulación de un proyecto asumido a partir de su latinoamericana significa incorporar una experiencia nueva al proyecto de la modernidad. Las acciones de arte, al colectivizar la experiencia social, la semantizan dotando al dolor individual de un valor específico en el espacio del arte y de la sociedad, interviniendo determinadas estructuras mentales, determinadas ideologías e imaginarios.

Esta expansión del significante del texto poético supone la utopía de la superación de la institución burguesa del arte y su reemplazo por una concepción en la que cada manifestación humana habría de considerarse artística. La expansión última del significante es convertir la vida misma en el espacio de la escritura. El único libro total (Mallarmé mediante) no sería otro que la vida misma.

La propuesta de Zurita ha ido a contrapelo de las claves poéticas dominantes y es éste un elemento a tener en cuenta. Me refiero a la insistencia por sostener un discurso utópico en tiempos en que prima el desencanto postmoderno, la clausura de los sentidos, la noción de lenguaje como fragmento, del sujeto como puro diferimiento. En su proyecto poco a poco se va imponiendo la noción de "sueño" como explicación de la energía que anima las posibilidades de transformación social. En este terreno mantiene la misma base utópica que alimentó sus primeros libros, pero desde el reemplazo de un discurso cultural y político a un discurso estético y ético. De hecho, Zurita abandona el uso de programas poéticos para pasar a una reflexión inserta en su misma escritura y a una evidente vocación para el desarrollo de la entrevista

incluye el siguiente texto: "El trabajo de ampliación de los niveles habituales de vida es el único montaje de arte válido / la única exposición / la única obra de arte que vale: cada hombre que trabaja para la ampliación aunque sea mental de sus espacios es una artista".

11 Raúl Zurita fundamenta de la siguiente manera este proyecto de escritura sobre Nueva York: "En 1981 sobre la ciudad de Nueva York realicé la primera parte del proyecto de escrituras en el cielo. Aviones con letras de humo blanco escribieron un poema de 15 frases, que se recortaron contra el azul del cielo neoyorkino. Al diseñar este proyecto, pensé que el cielo era precisamente aquel lugar hacia el cual todas las comunidades, desde los tiempos más inmemoriales, han dirigido sus miradas porque han creído ver allí las señas de sus destinos, y que entonces la más gran ambición a la que se podía aspirar es tener ese mismo cielo como página donde cualquiera pudiese escribir; recordando también en esto una frase de San Juan que decía: 'Vuestros nombres están grabados en el cielo"” (Zurita 1984: 35)

12 El texto completo es el siguiente y se encuentra reproducido en las distintas secciones de Anteparaíso: "mi Dios es hambre / mi Dios es nieve / mi Dios es no / mi Dios es desengaño / mi Dios es carroña / mi Dios es paraíso / mi Dios es pampa / mi Dios es chicano / mi Dios es cáncer / mi Dios es vacío / mi Dios es herida / mi Dios es ghetto / mi Dios es dolor / mi Dios es / mi amor de Dios".

${ }^{13}$ Sobre este proyecto Zurita ha señalado: "Al concebirlo recordé los sinnúmeros de jeroglíficos, de trazados, de signos, que pueblos en algún momento de su existencia realizaron como testimonios de sí mismos o como ofrecimiento a algo que venía del cielo. Las líneas de Nazca del Perú, los jeroglíficos de Atacama. Ese es el trasfondo de esta escritura física sobre el desierto... Es allí donde quise escribir, como un pequeño testimonio y homenaje a nuestro pasado, a los tiempos que vienen, a nuestra vida nueva". (Valdés Urrutia 1993: 24-25). 
como género adecuado para verter sus posiciones. La vida nueva implica una etapa de producción en la que el lirismo ocupa una posición central, pero no es menos cierto que su lenguaje mantiene una profunda tensión en la medida en que está atravesado por la violencia y el dolor ${ }^{14}$.

En este contexto no es extraño que nos encontremos con una resemantización, en términos humanistas, de conceptos o expresiones como "comunicación sagrada"15, "utopía"16 o "felicidad"17, y que la escritura sea vista nuevamente como una actividad motivada por impulsos superiores al propio poeta, transmisor de las contradicciones y de los sueños de su pueblo:

Estimo que los artistas somos realmente los intérpretes de los sueños y esperanzas de la comunidad. En algún momento pensé que la creación era una vocación de voluntad. Algo de eso hay sin duda, pero en el fondo los creadores son realmente los pueblos, quienes eligen a los artistas como sus transcriptores (Rodríguez 1988: 74).

La narración de sueños es, entonces, la explicación que encuentra para su actividad creadora. La poesía es articulación de los sueños colectivos y no de lo onírico personal (a la manera surrealizante). Este elemento es visible en Purgatorio y Anteparaíso, pero es en La vida nueva donde sueño y poesía se comprenden como actividad solidaria en la que entran en relación el poeta y su colectividad. Es necesario precisar que no se trata de la simple relación entre autor y lector, del intercambio comunicativo que siempre se ha supuesto entre estas instancias, sino que es necesario incorporar la noción del poeta como constructor de mitos que identifiquen a su comunidad y, por esta vía, resulta evidente el abandono de la idea parriana del poeta como destructor de mitos; la percepción de la actividad poética es, por lo tanto, deconstructoramente constructiva.

\section{CONCLUSIONES}

En estas páginas hemos advertido algunas modalidades que dicen relación con las interacciones entre discurso literario y artes visuales en un sentido amplio. No hemos considerado otras múltiples posibilidades que se pueden advertir en la poesía chilena de las tres últimas décadas. Me refiero, por ejemplo, a la utilización sistemática del ready made en Poemas encontrados y otros pretextos (1991) de Jorge Torres, que construye una notable exploración discursiva y visual a partir del recorte y ensamblaje de los más variados discursos (periodístico, poético, enciclopédico, entre otros); a la incorporación de registros fotográfico-etnográficos en De la tierra sin fuegos (1986), de Juan Pablo Riveros; a las transcripciones testimoniales y periodísticas en Naciste pintada (1999), de Carmen Berenguer; al poema comic en Joni Joy (2001), de Maha Vial; al poema filme en Tomás Harris; a las instalaciones y objetos poéticos en Poemas Visuales, de Nicanor Parra; a los videos poéticos de

\footnotetext{
${ }^{14}$ En más de una treintena de entrevistas que hemos revisado, Zurita insiste una y otra vez en que el propósito del arte es hacer que la vida sea más vivible, el mundo más habitable, de modo tal que recupera un estatuto claramente político y constructivo para la actividad artística, de claras connotaciones utópicas; al mismo tiempo en esta dinámica comienza a aparecer la noción de poeta como productor de bienes sociales más que estéticos, como traductor de aspiraciones colectivas más que individuales. El sentido utópico de su proyecto es pues una consecuencia de este modo de pensar: "purgatorio" y "anteparaíso" son palabras que sirven para explicar un determinado estado de cosas detrás de la cual se encuentra "la vida nueva": "En mi obra postulo la posibilidad del Paraíso. Y, a pesar de que toda la realidad te lo desmiente, yo creo que todos estamos construyendo el paraíso, que todo esto tiene un sentido..." (Maack 1985).

${ }^{15}$ La revitalización de un discurso utópico y trascendental en Zurita se advierte en afirmaciones como la siguiente: “... yo creo que nuestra lengua es el patético recuerdo de un estado de comunicación sagrada, mágica, vivencial y emotiva con todos los elementos de la realidad. O sea, el lenguaje que nosotros hablamos ya es ese recuerdo también; y a la vez atrae las condiciones en las cuales se impuso. Nosotros hablamos una lengua, el castellano, que hace quinientos años se impuso a sangre y fuego sobre este continente. Y cada vez que hablamos, de una u otra forma, traemos el recuerdo de esa especie de gran cataclismo que significó la conquista" (Epple 1994: 877).

${ }^{16}$ En cuanto a la relación entre utopía e historia Zurita señala: "Es verdad, son dos concepciones estrechamente ligadas, salvo que la utopía implica, en el fondo, el 'lugar de ninguna parte'. En ese sentido tiene valor histórico sólo como testimonio de un presente, no como futuro virtual al que se pueda acceder. En realidad, a través de distintas utopías, sociedades enteras han hablado de sí mismas, informando sobre sus sueños y sobre los dilemas de su presente" (Epple 1994: 867).
}

\footnotetext{
17 Sobre la aspiración humana de felicidad Zurita señala: "El lenguaje, que es lo único que tenemos, en ciertas ocasiones se revela sólo como la historia de un largo malentendido, de una especie de condena a la incompletud o la infelicidad. Cuando oigo decir que la misión de la poesía es la palabra, rescatar las palabras, pienso en realidad que es una afirmación que se hace con el pecho bajo. Que en realidad no es eso, sino el esfuerzo de transcribir esos grandes sueños y esas grandes pesadillas que gesta una comunidad o colectividad, y que siempre tienen relación con aquellas cosas que finalmente más le importan: el deseo de ser felices" (Epple 1994: 875).
} 
Enrique Lihn o José Ángel Cuevas; entre muchas otras posibilidades. En todos ellos, como en los casos que acabamos de analizar, nos encontramos no sólo frente a una ampliación de los soportes del discurso poético, sino también ante un cuestionamiento de las posibilidades de representación de lo real por parte de los discursos artísticos y en una desestabilización de las disciplinas y soportes que más allá de la palabra le aseguran su existencia en el sistema cultural.

$\mathrm{Si}$ atendemos a la noción de escritura que opera en los poetas analizados en estas páginas podemos advertir que ésta opera desde una fuerte conciencia no sólo de su materialidad, sino también como espacio de tensión cultural y política. La poesía es ante todo indagación semiótica y comunicacional; exploración en el significante, pero también en el espacio donde se deshace en sus complejas relaciones con los referentes. Escritura lúcida de su participación en el entramado ideológico que lo produce y que produce.

\section{OBRAS CITADAS}

CADA. 1982. "Una ponencia de CADA". Ruptura. Documento de Arte. Ediciones CADA.

Cánovas, Rodrigo. 1986. Lihn, Zurita, ICTUS, Radrigán: literatura chilena y experiencia autoritaria. Santiago de Chile: FLACSO.

Cárcamo, Luis Ernesto. 1990. "Poesía chilena: variedad vital". Literatura y Libros 103. La Epoca. 1 de abril.

Carrasco, Iván. 1989. "Poesía chilena de la última década (1977-1987)”, Revista Chilena de Literatura 33: 31-46.

Chihuailaf, Elicura y Eytel, Guido. 1985. “Gonzalo Millán: un poeta objetivista”. Poesía Diaria 6: 12-17.

De Nordenflycht C., José. 2001. El gran solipsismo. Juan Luis Martínez Obra Visual. Valparaíso: Puntángeles, UPLA.

Dubois, Gilbert. 1980. El manierismo. Barcelona: Península.

Epple, Juan Armando. 1994. “Transcribir el río de los sueños (entrevista a Raúl Zurita)”. Revista Iberoamericana 168-169.

Foucault, Michel. 1981. Esto no es una pipa. Barcelona: Anagrama.

Galindo, Oscar. 2000. "El alfabestiario universal de La Nueva Novela de Juan Luis Martínez", Revista Chilena de Literatura 21-40.

Hoefler, Walter. 1993. Modelos textuales (géneros y tipos) en la lírica hispanoamericana moderna. Tesis doctoral, Johann Wolfang Goethe-Universität, Frankfurt.

Lihn, Enrique. 1979. A partir de Manhattan. Santiago de Chile: Ganymedes.

Maack, Ana María. 1985. Entrevista "Raúl Zurita y su arte-pasión: El poeta camina siempre al borde del abismo". El Sur, Concepción, domingo 23 de junio.

Martínez, Juan Luis. 1977. La Nueva Novela. Santiago de Chile: Ediciones Archivo.

- 1978. La poesía chilena. Santiago de Chile: Ediciones Archivo.

Millán, Gonzalo. 2002. Claroscuro. Santiago de Chile: RIL.

Morales, Carla. 2006. Claroscuro de Gonzalo Millán: barroco y textualidad interartística. Tesis para optar al grado de Profesor de Lenguaje y Comunicación. Universidad Austral de Chile (Prof. Patrocinante Dr. Oscar Galindo V.).

Onetto, Breno. 2004. “Una mirada escéptica a la poesía concreta. Eugen Gomringer: ¿publicista o poeta?”. Estudios Filológicos 39. 191-202.

Recanati, Francois. 1981. La transparencia y la enunciación. Buenos Aires: Librería Hachette.

Richard, Nelly. 1994. "Una cita limítrofe entre neovanguardia y postvanguardia", La insubordinación de los signos (Cambio político, transformaciones culturales y poéticas de la crisis). Santiago de Chile: Cuarto Propio.

Rodríguez O., Mario. 1988. "Raúl Zurita, poeta: Quisiera lanzar un grito de humanidad que vaya más allá de lo estrictamente político". Cosas 311.1 de septiembre.

Sucre, Guillermo. 1985. "La trampa de la historia". La máscara, la transparencia. Ensayos sobre poesía hispanoamericana. México: FCE. 278-292.

Triviños, Gilberto. 1988. "El regreso". Alonso, María Nieves y otros. Las plumas del colibrí. Quince años de poesía en Concepción (1973-1988). Estudio y antología. Santiago de Chile: INPRODE-CESOC. 53-107.

Ulibarri, Luisa. 1987. "Raúl Zurita canta a los ríos que conversan y se aman", La Epoca, 7 de abril.

Valdés Urrutia, Cecilia. 1993. entrevista: "Nace La vida nueva”, El Mercurio, 25 de julio. 24-25.

Zurita, Raúl. 1979. "Nel mezzo del cammin", Cal 2. 10.

—. 1979. Purgatorio. Santiago de Chile: Universitaria.

—. 1982. Anteparaíso. Santiago de Chile: Editores Asociados. 
- 1984. "Antología imaginaria. Escrituras en el cielo", Revista Universitaria 11. 35.

_ 1994. La vida nueva. Santiago de Chile: Universitaria. 